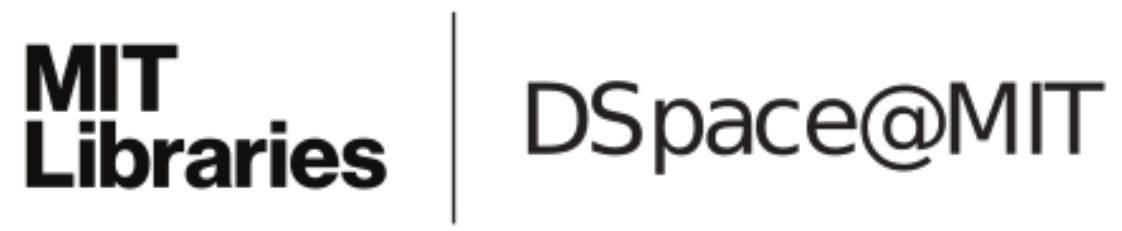

\author{
MIT Open Access Articles
}

Breaking the Base Barrier: An ElectronDeficient Palladium Catalyst Enables the Use of a Common Soluble Base in C-N Coupling

The MIT Faculty has made this article openly available. Please share how this access benefits you. Your story matters.

Citation: Dennis, Joseph M. et al. "Breaking the Base Barrier: An Electron-Deficient Palladium Catalyst Enables the Use of a Common Soluble Base in C-N Coupling." Journal of the American Chemical Society 140, 13 (March 2018): 4721-4725 @ 2018 American Chemical Society

As Published: http://dx.doi.org/10.1021/jacs.8b01696

Publisher: American Chemical Society (ACS)

Persistent URL: https://hdl.handle.net/1721.1/125953

Version: Author's final manuscript: final author's manuscript post peer review, without publisher's formatting or copy editing

Terms of Use: Article is made available in accordance with the publisher's policy and may be subject to US copyright law. Please refer to the publisher's site for terms of use. 
Published in final edited form as:

J Am Chem Soc. 2018 April 04; 140(13): 4721-4725. doi:10.1021/jacs.8b01696.

\title{
Breaking the Base Barrier: An Electron-Deficient Palladium Catalyst Enables the Use of a Common Soluble Base in $\mathbf{C}-\mathbf{N}$ Coupling
}

\author{
Joseph M. Dennis ${ }^{\dagger}$, Nicholas A. White ${ }^{\dagger}$, Richard Y. Liu, and Stephen L. Buchwald ${ }^{\star}$ \\ Department of Chemistry, Massachusetts Institute of Technology, Cambridge, Massachusetts \\ 02139, United States
}

\begin{abstract}
Due to the low intrinsic acidity of amines, palladium-catalyzed $\mathrm{C}-\mathrm{N}$ cross-coupling has been plagued continuously by the necessity to employ strong, inorganic, insoluble bases. To surmount the many practical obstacles associated with these reagents, we utilized a commercially available dialkyl triarylmonophosphine-supported palladium catalyst that facilitates a broad range of $\mathrm{C}-\mathrm{N}$ coupling reactions in the presence of weak, soluble bases. The mild and general reaction conditions show extraordinary tolerance for even highly base-sensitive functional groups. Additionally, insightful heteronuclear NMR studies using ${ }^{15} \mathrm{~N}$-labeled amine complexes provide evidence for the key acidifying effect of the cationic palladium center.
\end{abstract}

\section{Graphical Abstract}

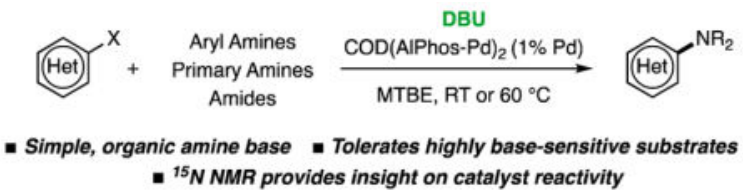

\section{INTRODUCTION}

Palladium-catalyzed carbon-nitrogen $(\mathrm{C}-\mathrm{N})$ bond formation has become a valuable tool in the modern synthesis of structurally complex target molecules. Over the last two decades, numerous methods have been established for the coupling of aryl halide and pseudohalide electrophiles with several classes of amine nucleophiles in the presence of base. ${ }^{1}$ A number of improvements in the development of ligands ${ }^{2}$ and precatalysts ${ }^{3}$ have taken place. Despite considerable effort, there has been no general and practical solution to allow for the use of

\footnotetext{
Corresponding Author: sbuchwal@mit.edu.

†uthor Contributions

J.M.D. and N.A.W. contributed equally to this work.

The authors declare the following competing financial interest(s):

MIT has filed patents on ligands and precatalysts that are described in this manuscript, from which S.L.B and former co-workers receive royalty payments.

Supporting Information

Experimental procedures, computational, spectral, and reaction optimization data, discussion of ${ }^{31} \mathrm{P}-1{ }^{15} \mathrm{~N} 2 \mathrm{~J}$ couplings, and X-ray data.
} 
amine bases in Pd-catalyzed C-N cross-coupling. Because the majority of current catalytic systems utilize inorganic bases, modern amination methods suffer from restrictions with regard to functional group compatibility or other operational limitations due to insolubility (Figure 1). ${ }^{4}$ For instance, metal alkoxide and lithium amide bases are moisture-sensitive and are incompatible with functional groups that are prone to nucleophilic attack either by base or by base-activated amine. ${ }^{5}$ As an alternative, inorganic bases such as $\mathrm{Cs}_{2} \mathrm{CO}_{3}, \mathrm{~K}_{3} \mathrm{PO}_{4}$, and $\mathrm{K}_{2} \mathrm{CO}_{3}$ are frequently employed, but because of their insolubility, reactions often require a phase transfer agent or high catalyst loadings, as well as elevated reaction temperatures. ${ }^{6}$ Furthermore, because deprotonation likely takes place on the particle surface of the base in heterogeneous systems, the use of these bases introduces reproducibility issues on large scales when stirring methods ${ }^{7}$ or particle sizes ${ }^{8}$ are varied. Finally, due to their insolubility in most organic solvents, these bases also pose challenges for continuous flow chemistry ${ }^{9}$ and in reagent dosing for robotic miniaturization methods, which has stifled usage of industrial technologies. Thus, the discovery of a catalyst system that facilitates the coupling of multiple amine classes in the presence of a weak, amine base would provide an important solution to this long-standing synthetic challenge. Herein, we report the first general solution to this problem. Moreover, we have uncovered the factors that enable the success of such a system, which should help guide the future discovery of even more active catalytic systems.

Organic bases are employed infrequently in $\mathrm{C}-\mathrm{N}$ coupling methodologies despite their widespread use in synthesis, broad $\mathrm{p} \mathrm{K}_{\mathrm{BH}}{ }^{+}$range, suitability for continuous flow chemistry, and compatibility with electrophilic functional groups (Figure 2). ${ }^{10}$ In one example, organic phosphazene bases such as $\mathrm{P}_{2}$-Et have been used in nanomolar, robotic high-throughput screening to couple a variety of nucleophiles. ${ }^{11}$ While effective, phosphazene bases are expensive and must be stored in an inert atmosphere. ${ }^{12}$ Weaker organic amine bases such as 1,8-diazabicyclo[5.4.0]undec-7-ene (DBU) and 7-methyl-1,5,7-triazabicyclo[4.4.0]dec-5ene (MTBD) have been employed in $\mathrm{C}-\mathrm{N}$ coupling of aryl nonaflates under microwave radiation. ${ }^{13}$ However, only simple anilines could be coupled using DBU while heteroaryl amines required the moisture-sensitive and expensive MTBD. Utilizing photoredox catalysis, $\mathrm{C}-\mathrm{N}$ coupling has been performed with 1,4-diazabicyclo[2.2.2] octane (DABCO) as the base. ${ }^{14}$ Despite the mild nature of this method, $\mathrm{C}-\mathrm{N}$ couplings facilitated by photoredox processes are primarily focused on aliphatic amine nucleophiles. Finally, a few examples of electrochemically-mediated, nickel-catalyzed amidation and amination of aryl bromides have been reported with DBU as the base. ${ }^{15}$ In hopes of overcoming current limitations of these methodologies, we aimed to develop a system that utilizes commercially available ligands and a weak organic base to couple a variety of amine classes.

\section{RESULTS AND DISCUSSION}

Our efforts focused on whether commonly used dialkyl biarylmonophosphine ligands could facilitate the coupling of aryl halides or triflates with amines using soluble organic bases. Initial stoichiometric experiments using oxidative addition (OA) complexes (See Supporting Information) indicated that weaker bases such as triethylamine (TEA) and DABCO were outperformed by DBU in procedures using many different ligands when coupling aryl amines, amides, and primary amines. Experiments utilizing $p$-tolyl-OA complexes (Figure 1, II) as catalysts $(1.0 \mathrm{~mol} \%)$ to couple $p$-tolyl triflate with aniline revealed that multiple 
ligands are capable of facilitating the desired reaction (Table 1). Precatalyst $\mathbf{P 6}$ bearing $\mathbf{L 6}$ (AlPhos) ${ }^{16}$ and $\mathbf{P 5}$ (AdBrettPhos) provided nearly quantitative cross-coupling product at room temperature. $\mathbf{P 4}$ ( $t$-BuBrettPhos) provided the desired product in moderate yields, ${ }^{17}$ and ligands bearing cyclohexyl (Cy) groups on the phosphine, including P3 (BrettPhos) and $\mathbf{L 1}$ (XPhos) failed to yield any of the desired product. While $\mathbf{P 5}$ is highly reactive, the ligand from which it is derived is known to undergo an in situ ligand modification in the presence of aryl (pseudo)halides, generating different active catalytic species for each ArX substrate. ${ }^{18}$ As a result, the commercially available, air-stable, L6-supported precatalyst, $\operatorname{COD(L6-~}$ $\mathrm{Pd})_{2}$, was selected for further investigation in $\mathrm{C}-\mathrm{N}$ coupling with amines of varying $\mathrm{p} K \mathrm{a}$ and nucleophilicity. When coupling benzamide with the aryl triflate, $76 \%$ yield was obtained, with unreacted electrophile making up the mass balance. Upon raising the temperature to $60{ }^{\circ} \mathrm{C}$, the yield was increased to $97 \%$. Similar reactivity was observed with benzyl amine, demonstrating that this ligand facilitates the coupling of different amine classes.

To explore the scope of the methodology, a variety of aryl halides, triflates, and nucleophiles were tested (Table 2). Both five- and six-membered heterocyclic amines, including a pyrazine (1a), a thiazole (1e), and an oxazole (1i) were coupled in high yield under the optimized reaction conditions. Substrates bearing acidic functional groups, such as an unprotected pyrazole (1d, $\mathbf{1 f})$, an indole $(\mathbf{1 b}, \mathbf{1 h}, \mathbf{3 d}, \mathbf{3 f})$, and a phenol $(\mathbf{1 c}, \mathbf{3 c})$, are also compatible with the weakly basic reaction conditions when an excess of base is used. Importantly, five-membered heterocyclic bromides are competent in the reaction, as well as highly functionalized electrophiles such as the Merck informer compound, X18 (1f). Using $0.2 \mathrm{~mol} \%$ of Pd, $\mathbf{1 g}$ was prepared at room temperature in $95 \%$ yield after crystallization on a $10 \mathrm{mmol}$ scale. Amide-type coupling partners, including an oxazolidinone (2b), a primary urea $(\mathbf{2 g})$, and a secondary cyclic amide (2d) underwent the desired arylation reaction in good to excellent yields. Heterocyclic amides, including pyridines (2c, 2e), a furan (2h), and a thiophene (2f) are tolerated, though these substrates required diluted reaction conditions due to their low solubility. Similarly, heterocyclic products derived from aliphatic amine coupling partners are obtained in high yields. In cases where standard reaction conditions show low conversion to product, excess base and amine were employed (3e). Hindered aliphatic amines, including secondary aliphatic amines, proved to be difficult substrates under the reaction conditions, most likely due to unfavorable steric interactions near the Pd center. Relative to $\mathrm{COD}(\mathbf{L 6} 6-\mathrm{Pd})_{2}, t$-BuBrettPhos-G3 provides 1d and $\mathbf{1 f}$ in comparable yields (Table 2, red numbers) with $1.0 \mathrm{~mol} \%$ of Pd, while 1a, and $2 \mathrm{e}$ require higher loadings. We note that the L4-supported precatalyst fails to couple primary amines under these conditions.

Due to the mildness of the reaction conditions, we envisioned that this methodology would be amenable to substrates that would readily undergo undesired elimination and substitution reactions in the presence of strong bases. For example, Hartwig has shown that fluoroalkylamines participate in base-promoted decomposition reactions. ${ }^{19}$ In our system, these amines are readily coupled at room temperature without decomposition (Table 3, 4c). Moreover, elimination-prone coupling partners bearing alkyl halide functional groups, including unhindered primary bromides $(\mathbf{4 a})$ and chlorides $(\mathbf{4 b}, \mathbf{4 d})$, are suitable coupling partners. When subjected to previously developed conditions, these coupling partners and 
products were found to undergo elimination reactions to yield the corresponding alkenes; however, under our reaction conditions, the alkyl halide provides opportunities for subsequent synthetic elaboration.

In both stoichiometric and catalytic experiments, we observed that ligands bearing large alkyl groups performed better than smaller variants. Inspired by the work of Tyler, we hypothesized that the size of the alkyl groups on the phosphine might affect the electrophilicity of palladium through geometric distortion at the phosphorus atom. ${ }^{20}$ In turn, these size effects should influence the acidity of Pd-bound amines. Specifically, the magnitude of this acidifying effect directly affects the ease of the key deprotonation step ${ }^{21}$ and consequently dictates the strength of base that is required. ${ }^{2 \mathrm{~d}, 4 \mathrm{a}}$ The structure of an amine-bound OA complex (Figure 1, III) was elucidated by single crystal X-ray diffraction, which indicated that the amine was bound trans to the phosphine (Figure 3). Analogous complexes bearing a ${ }^{15} \mathrm{~N}$-enriched $n$-butyl amine were used to study the effect of ligand bulkiness on the central Pd atom charge (Table 4). NMR spectroscopic analyses of the twobond ${ }^{31} \mathrm{P}-{ }^{15} \mathrm{~N}$ coupling for AlPhos and BrettPhos ligand families indicated that the ligands bearing larger alkyl groups exhibited smaller coupling constants ( $\mathrm{Ad}<t-\mathrm{Bu}<\mathrm{Cy}$ ). ${ }^{22}$ The magnitude of the trans ${ }^{31} \mathrm{P}-{ }^{15} \mathrm{~N}^{2} J$ constant is directly influenced by the electron-donation to the Pd atom: specifically, more cationic (at Pd) amine-bound complexes exhibit less negative ${ }^{2} \boldsymbol{J}$ values (see Supporting Information for discussion). ${ }^{23}$ Thus, the trend we observed indicates that the Ad ligands are the least electron-donating, a conclusion that is consistent with our DFT calculated Hirshfeld charges at Pd. Of the intermediates analyzed, the smallest ${ }^{2} J$ was observed with AlPhos (L6) as the supporting ligand, suggesting that the amine bound to this complex is most easily deprotonated. We propose that this explains the superior performance of $\mathbf{L 6}$ in reactions promoted by weak bases.

\section{CONCLUSION}

In summary, we have developed a catalyst system that utilizes a weak organic amine base in the coupling reaction of aryl (pseudo)halides with a variety of amine and amide partners. The electrophile scope includes five- and six-membered heterocycles, as well as alkyl halide functional groups that were not tolerated by previously developed conditions. While L6 is the most generally effective ligand, we found that more traditional ligands such as $\mathbf{L} \mathbf{4}$ can be economical substitutes for some aryl amine and amide couplings. We show that the size of the phosphine substituents modulates the charge on the Pd atom, with $\mathbf{L 6}$ generating the most cationic, and thus most active, amine-Pd complex. Ongoing work is focused on a more detailed understanding of the reaction mechanism.

\section{Supplementary Material}

Refer to Web version on PubMed Central for supplementary material.

\section{Acknowledgments}

This material is based upon work supported by the NSF Graduate Research Fellowship Program under Grant No. 1122374 (J.M.D.), an NIH Postdoctoral Fellowship under Grant No. 1F32GM120847-01 (N.A.W.), and the NIH (Grant Nos. GM122483 and GM58160). Any opinions, findings, conclusions, or recommendations expressed in this material are those of the authors and do not necessarily reflect the views of the NSF or NIH. R.Y.L. thanks Bristol- 
Myers Squibb for a Fellowship in Synthetic Organic Chemistry. We acknowledge several companies for donations of chemicals used in this work: Sigma-Aldrich for BrettPhos and $t$-BuBrettPhos, Nippon Chemical for cyclohexyl chlorophosphine, FMC Lithium for tert-butyl chlorophosphine, and Merck for informer compound X18. We are grateful to Dr. Peter Müller for crystallographic analysis, and we acknowledge Dr. Andy Thomas and Dr. Christine Nguyen for assistance in the preparation of this manuscript.

\section{References}

1. Ruiz-Castillo P, Buchwald SL. Chem Rev. 2016; 116:12564-12649. [PubMed: 27689804]

2. Surry DS, Buchwald SL. Angew Chem Int Ed. 2008; 47:6338-6361.Hartwig JF. Acc Chem Res. 2008; 41:1534-1544. [PubMed: 18681463] Fleckenstein CA, Plenio H. Chem Soc Rev. 2010; 39:694-711. [PubMed: 20111788] Wolfe JP, Wagaw S, Marcoux JF, Buchwald SL. Acc Chem Res. 1998; 31:805-818.Schlummer B, Scholz U. Adv Synth Catal. 2004; 346:1599-1626.. For recent examples of rationally designed dialkyl biarylmonophosphine ligands, see: Olsen EPK, Arrechea PL, Buchwald SL. Angew Chem Int Ed. 2017; 56:10569-10572.Park NH, Vinogradova EV, Surry DS, Buchwald SL. Angew Chem Int Ed. 2015; 54:8259-8262.Ruiz-Castillo P, Blackmond DG, Buchwald SL. J Am Chem Soc. 2015; 137:3085-3092. [PubMed: 25651374]

3. (a) Ingoglia BT, Buchwald SL. Org Lett. 2017; 19:2853-2856. [PubMed: 28498667] (b) Bruno NC, Niljianskul N, Buchwald SL. J Org Chem. 2014; 79:4161-4166. [PubMed: 24724692] (c) Pompeo M, Farmer JL, Froese RDJ, Organ MG. Angew Chem Int Ed. 2014; 53:3223-3226.

4. For improvements to previous conditions, see: Wolfe JP, Buchwald SL. Tetrahedron Lett. 1997; 38:6359-6362.Harris MC, Huang X, Buchwald SL. Org Lett. 2002; 4:2885-2888. [PubMed: 12182580]

5. Sperry JB, Wiglesworth KEP, Edmonds I, Fiore P, Boyles DC, Damon DB, Dorow RL, Piatnitski Chekler EL, Langille J, Coe JW. Org Process Res Dev. 2014; 18:1752-1758.

6. Surry DS, Buchwald SL. Chem Sci. 2011; 2:27-50. [PubMed: 22432049]

7. Kuethe JT, Childers KG, Humphrey GR, Journet M, Peng Z. Org Process Res Dev. 2008; 12:12011208.

8. Meyers C, Maes BUW, Loones JTJ, Bal G, Lemière GLF, Dommise RA. J Org Chem. 2004; 69:6010-6017. [PubMed: 15373485]

9. (a) Yang JC, Niu D, Karsten BP, Lima F, Buchwald SL. Angew Chem Int Ed. 2016; 55:2531-2535. (b) Noël T, Naber JR, Hartman RL, McMullen JP, Jensen KF, Buchwald SL. Chem Sci. 2011; 2:287-290.(c) Falß S, Tomaiuolo G, Perazzo A, Hodgson P, Yaseneva P, Zakrzewski J, Guido S, Lapkin A, Woodward R, Meadows RE. Org Process Res Dev. 2016; 20:558-567.

10. For computational studies on soluble bases in Pd-catalyzed C-N coupling, see: Sunesson Y, Limé E, Nilsson Lill SO, Meadows RE, Norrby P-O. J Org Chem. 2014; 79:11961-11969. [PubMed: 25340530]. In some cases, soluble bases may be employed to enhance reactions that do not require bases: Murthy Bandaru SS, Bhilare S, Chrysochos N, Gayakhe V, Trentin I, Schulzke C, Kapdi AR. Org Lett. 2018; 20:473-476. [PubMed: 29303597]

11. Buitrago Santanilla A, Christensen M, Campeau L-C, Davies IW, Dreher SD. Org Lett. 2015; 17:3370-3373. [PubMed: 26099020] . For applications of soluble superbases, see: Buitrago Santanilla A, Regalado EL, Pereira T, Shevlin M, Bateman K, Campeau L-C, Schneeweis J, Berritt S, Shi ZC, Nantermet P, Liu Y, Helmy R, Welch CJ, Vachal P, Davies IW, Cernak T, Dreher SD. Science. 2015; 347:49-53. [PubMed: 25554781] . The use of $\mathrm{P}_{2}$-Et, MTBD, and 2-tertButyl-1,1,3,3-tetramethylguanidine (BTMG)in the Pd-catalyzed coupling of aryl amines and aryl halides was reported while this manuscript was under review: Ahneman DT, Estrada JE, Lin S, Dreher SD, Doyle AG. Science.

12. Schwesinger R, Hasenfratz C, Schlemper H, Walz L, Peters E-M, Peters K, von Schnering HG. Angew Chem Int Ed Engl. 1993; 32:1361-1363.

13. Tundel RE, Anderson KW, Buchwald SL. J Org Chem. 2006; 71:430-433. [PubMed: 16388678]

14. Corcoran EB, Pirnot MT, Lin S, Dreher SD, DiRocco DA, Davies IW, Buchwald SL, MacMillan DWC. Science. 2016; 353:279-283. [PubMed: 27338703]

15. Li C, Kawamata Y, Nakamura H, Vantourout JC, Liu Z, Hou Q, Bao D, Starr JT, Chen J, Yan M, Baran PS. Angew Chem Int Ed. 2017; 56:13088-13093. 
16. Sather AC, Lee HG, De La Rosa VY, Yang Y, Müller P, Buchwald SL. J Am Chem Soc. 2015; 137:13433-13438. [PubMed: 26413908]

17. In high-throughput reaction screening, this ligand was found to be suitable for amide couplings facilitated by DBU. See reference 11a.

18. Milner PJ, Maimone TJ, Su M, Chen J, Müller P, Buchwald SL. J Am Chem Soc. 2012; 134:19922-19934. [PubMed: 23153301]

19. Brusoe AT, Hartwig JF. J Am Chem Soc. 2015; 137:8460-8468. [PubMed: 26065341]

20. Kendall AJ, Zakharov LN, Tyler DR. Inorg Chem. 2016; 55:3079-3090. [PubMed: 26913633]

21. Preliminary mechanistic studies have indicated that there is a positive order in [DBU] for the coupling of $p$-tolyl triflate and propyl amine. This suggests that the base is involved in the turnover-limiting step.

22. For examples of this effect observed in methylene groups, see: Cahill R, Cookson RC, Crabb TA. Tetrahedron. 1969; 25:4681-4709.Cahill R, Cookson RC, Crabb TA. Tetrahedron. 1969; 25:47114735.Fraser RR, Raby BF. J Am Chem Soc. 1972; 94:3458-3463.

23. The variation in ${ }^{2} \mathrm{~J}$ values $(\sim 1.0 \mathrm{~Hz})$ is in the range of those observed in ${ }^{2} \mathrm{~J}$ coupling constants of ${ }^{13} \mathrm{C}-\mathrm{Au}-{ }^{31} \mathrm{P}$ complexes bearing trialkyl and triaryl phosphine ligands. For studies on the effect of phosphine size on two-bond coupling, see: Isab AA, Hussain MS, Akhtar MN, Wazeer MIM, AlArfaj AR. Polyhedron. 1999; 18:1401-1409. 


\section{A. Proposed Catalytic Cycle}

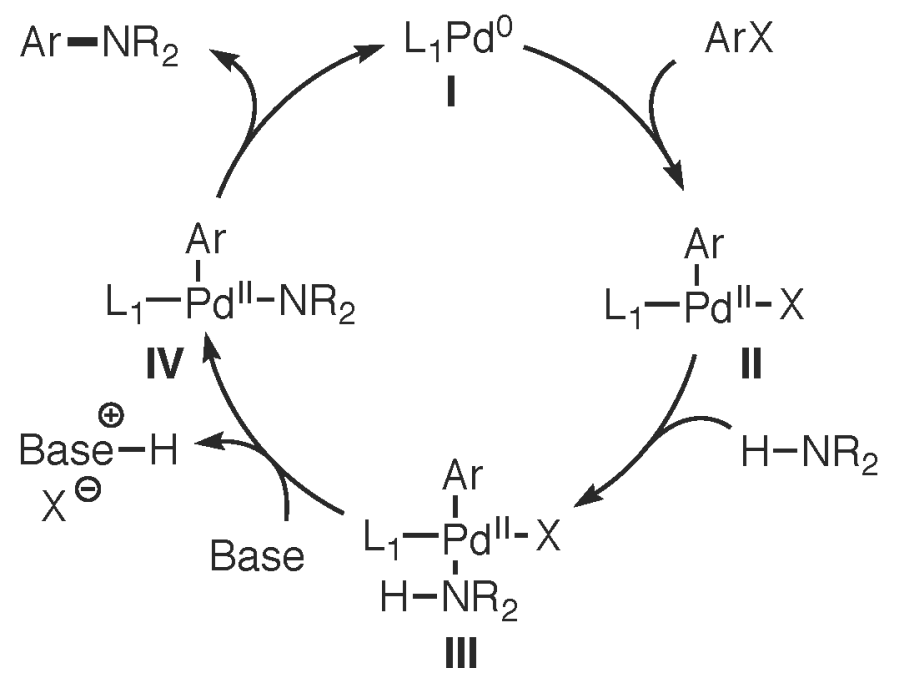

B. Anionic, Nucleophilic Bases

- NaOt-Bu, LHMDS

- Incompatible with many electrophilic functional groups

- Moisture sensitive Inorganic, Insoluble Bases

- $\mathrm{K}_{3} \mathrm{PO}_{4}, \mathrm{~K}_{2} \mathrm{CO}_{3}, \mathrm{Cs}_{2} \mathrm{CO}_{3}$

- Difficult to stir on scale

- Particle size can affect reactivity

- Can require higher Pd loadings

Figure 1.

(A) The proposed catalytic cycle for the palladium-catalyzed coupling of aryl halides with amines: I, monoligated $\mathrm{Pd}(0)$; II, oxidative addition (OA) complex; III, amine-bound OA complex; IV, amido complex. (B) Synthetic considerations for bases employed in $\mathrm{C}-\mathrm{N}$ coupling. 
I. Phosphazene Base-Promoted Couplings (Dreher, Merck)

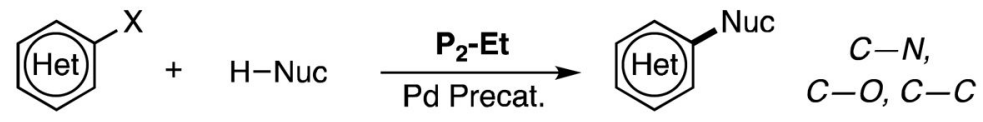

$\mathrm{X}=\mathrm{Br}, \mathrm{Cl}, \mathrm{I}$

II. Microwave-Assisted Aminations (Buchwald)

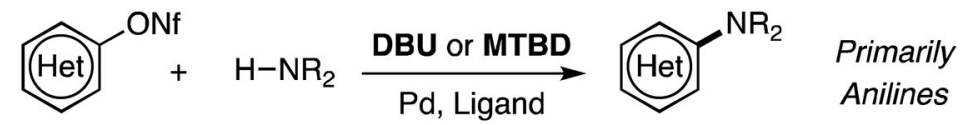

$$
\begin{aligned}
& \mathrm{Nf}=\mathrm{SO}_{2}\left(\mathrm{CF}_{2}\right)_{3} \mathrm{CF}_{3} \quad \mu \mathrm{W}\left(115-175^{\circ} \mathrm{C}\right)
\end{aligned}
$$

III. Photoredox Catalysis (MacMillan)

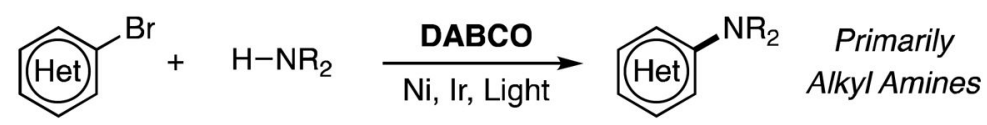

IV. Electrochemically Enabled Amination (Baran)

$$
\stackrel{\mathrm{Het}}{\mathrm{Br}}+\mathrm{HR}_{2} \underset{\substack{\mathrm{Ni}, \text { Ligand } \\
\mathrm{RVC}(+) / \mathrm{Ni}(-)}}{\stackrel{\mathrm{DBU}}{\mathrm{NR}_{2}}} \begin{gathered}
2^{\circ} \text { Amines } \\
\text { and Amides }
\end{gathered}
$$

Figure 2.

Current metal-catalyzed $\mathrm{C}-\mathrm{N}$ coupling methodologies that utilize soluble, amine bases. 

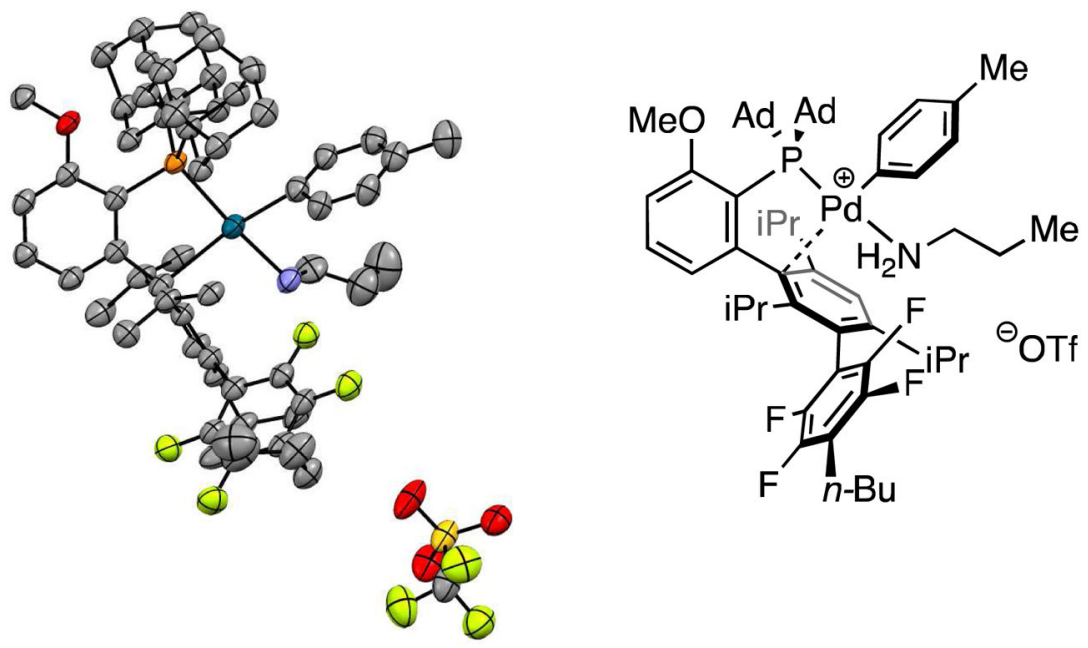

Figure 3.

Propyl-amine-bound L6-supported OA complex. Thermal ellipsoids are shown at 50\% probability. Hydrogen atoms and residual toluene molecules are omitted for clarity. 


\section{Table 1}

Comparison of Ligands in Pd-Catalyzed Amination Facilitated by DBU ${ }^{a}$

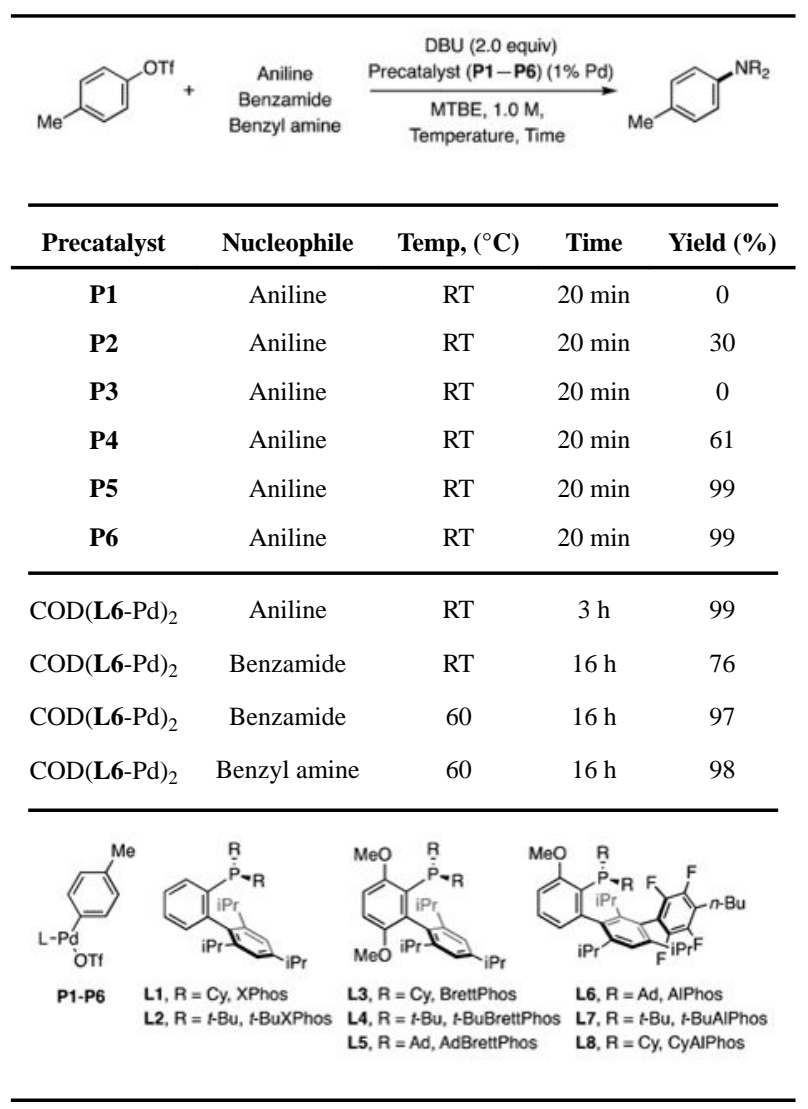

${ }^{a}$ Reaction conditions: aryl triflate $(0.25 \mathrm{mmol})$ nucleophile $(0.30 \mathrm{mmol})$, DBU $(0.50 \mathrm{mmol})$, precatalyst $(1 \% \mathrm{Pd}$; $2.5 \mu \mathrm{mol}$ or $1.25 \mu \mathrm{mol}$ dimer $)$, MTBE $(0.25 \mathrm{~mL})$. GC and ${ }^{1} \mathrm{H}$ NMR yields referenced to hexamethylbenzene as an internal standard. MTBE = methyl tert-butyl ether. 
Table 2

Amination and Amidation of Aryl Triflates, Bromides, and Chlorides ${ }^{a}$

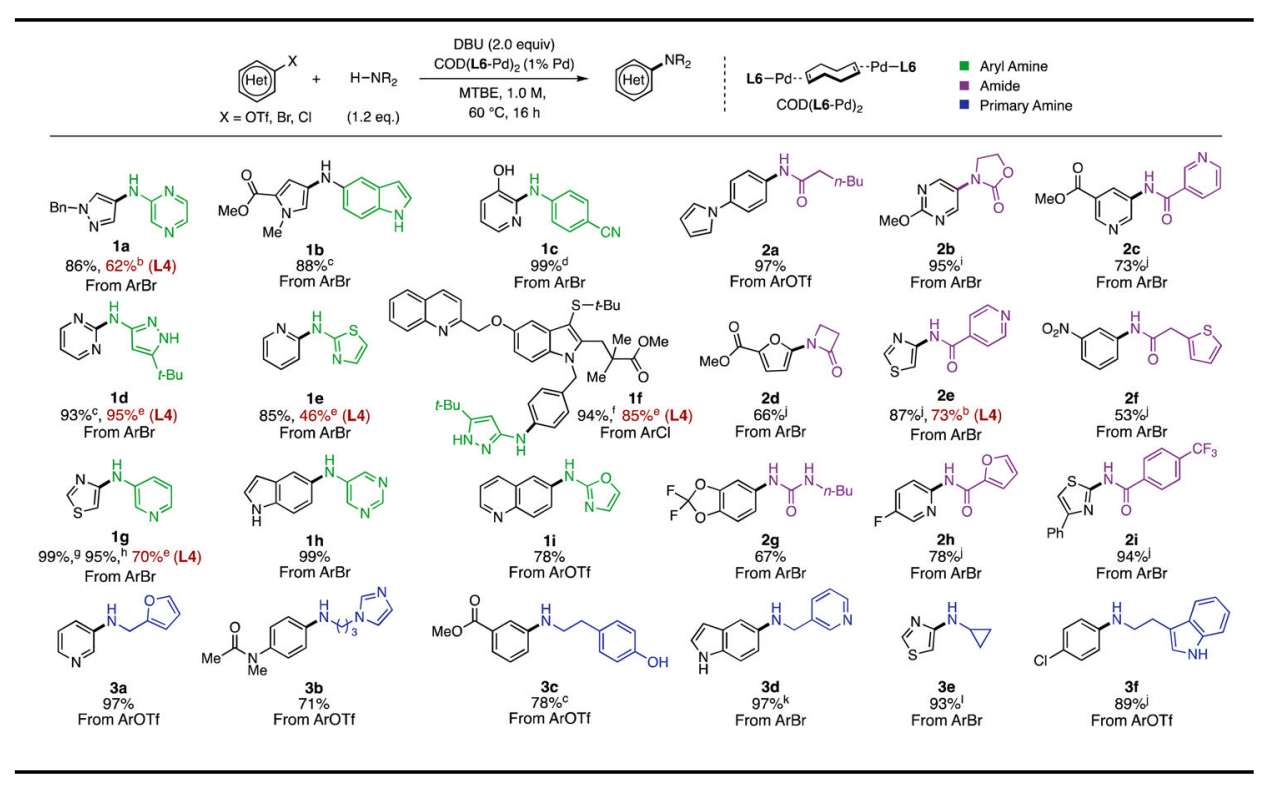

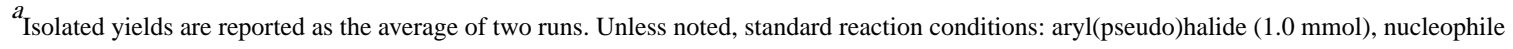
$(1.2 \mathrm{mmol}), \mathrm{DBU}(2.0 \mathrm{mmol}), \mathrm{COD}(\mathbf{L 6}-\mathrm{Pd})^{2}(0.005 \mathrm{mmol}, 1 \% \mathrm{Pd}), \mathrm{MTBE}(1.0 \mathrm{~mL}, 1 \mathrm{M}), 60^{\circ} \mathrm{C}$ for $16 \mathrm{~h}$. While these conditions are suitable for each substrate, in many cases milder conditions can be used. Red yields indicate reactions performed with L4-G3 under substrate-specific conditions.

$b_{3 \% \text { L4-G3 }}$

$c_{4.0}$ equiv of base.

$d_{3 \mathrm{~h}}$ at RT, 4.0 equiv of DBU.

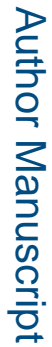

$e_{1 \% \mathbf{L} 4-\mathrm{G} 3}$.

$f_{0.50 \mathrm{mmol}, 0.5 \mathrm{M} \text { in THF. }}$

$g_{3 \mathrm{~h} \text { at RT. }}$

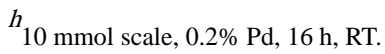

$i_{0.25 \mathrm{M}, 0.95 \text { equiv of nucleophile. }}$

$j_{0.25 \mathrm{M}}$.

$k_{2 \%} \mathrm{Pd}, 4.0$ equiv of DBU.

$1_{4.0}$ equiv of DBU and amine, $50^{\circ} \mathrm{C}$. 


\section{Table 3}

Base-Sensitive Coupling Partners

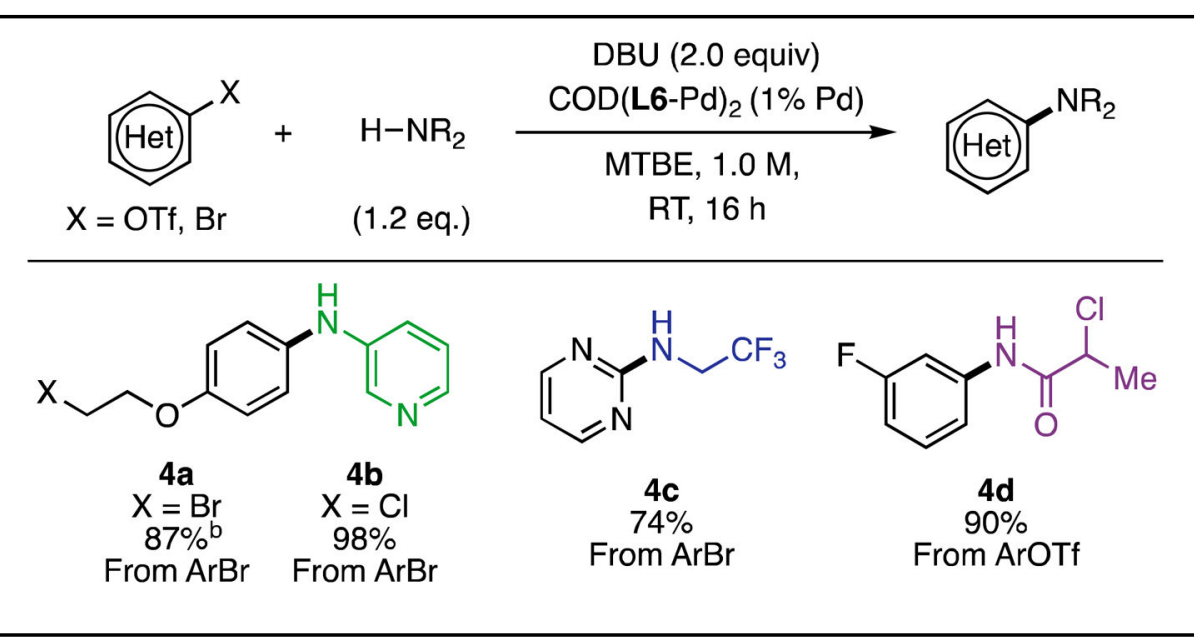

Isolated yields are reported as the average of two runs. Unless noted, standard reaction conditions: aryl(pseudo)halide (1.0 mmol), nucleophile (1.2 mmol), DBU (2.0 mmol), COD(L6-Pd $)^{2}(0.005 \mathrm{mmol}, 1 \% \mathrm{Pd})$, MTBE (1.0 mL, $\left.1 \mathrm{M}\right)$, RT for $16 \mathrm{~h}$.

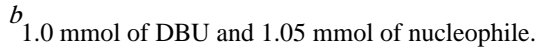




\section{Table 4}

${ }^{31} \mathrm{P} \_{ }^{15} \mathrm{~N}{ }^{2} \mathrm{~J}$ Coupling Constants ${ }^{a}$

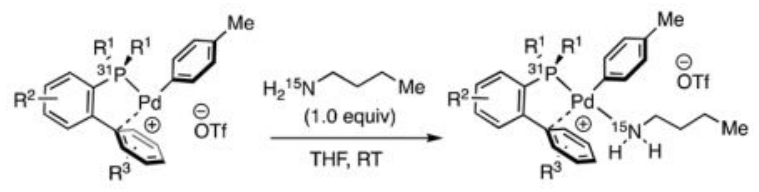

\begin{tabular}{cccc}
\hline Ligand & Alkyl Group $\left(\mathbf{R}^{\mathbf{1}}\right)$ & ${ }^{2} \mathbf{J}\left({ }^{\mathbf{3}} \mathbf{P}-{ }^{15} \mathbf{N}\right)(\mathbf{H z})$ & Pd Charge (Hirshfeld, 10 $\left.\mathbf{1 0}^{\mathbf{3}} \mathbf{e}\right)$ \\
\hline BrettPhos (L3) & $\mathrm{Cy}$ & -37.0 & +186 \\
$t$-BuBrettPhos (L4) & $t$-Bu & -36.1 & +191 \\
AdBrettPhos (L5) & $\mathrm{Ad}$ & -35.2 & +195 \\
\hline CyAIPhos (L8) & $\mathrm{Cy}$ & -35.9 & +194 \\
f-BuAIPhos (L7) & $t$-Bu & -35.1 & +203 \\
AIPhos (L6) & Ad & -34.2 & $\mathbf{+ 2 0 3}$ \\
\hline
\end{tabular}

${ }^{a}$ Hirshfeld charges were computed at the B3LYP/6-31G(d)-SDD/SMD(THF)) level of theory with geometries optimized at the same level. 